\title{
Influence of Heat Treatment on Precipitation Behavior and Mechanical Properties of Extruded AZ80 Magnesium Alloy
}

\author{
Xi Zhao ${ }^{1} \cdot \mathrm{Fa}-\mathrm{Fa} \mathrm{Yan}{ }^{2} \cdot$ Zhi-Min Zhang $^{3} \cdot$ Peng-Cheng Gao ${ }^{4} \cdot$ Shu-Chang $\mathrm{Li}^{2}$
}

Received: 12 March 2020 / Revised: 15 April 2020 / Accepted: 17 April 2020 / Published online: 30 June 2020

(C) The Chinese Society for Metals (CSM) and Springer-Verlag GmbH Germany, part of Springer Nature 2020

\begin{abstract}
By means of annular channel angular extrusion technology and solution treatment, the AZ80 supersaturated solid solution was prepared. The $\beta$ - $\mathrm{Mg}_{17} \mathrm{Al}_{12}$ precipitate morphologies analysis along with its sizes and area fraction measurement was performed to investigate mechanical properties variation of alloy at various aging temperature. The results indicated that after solution treatment, the intergranular precipitate of as-extruded alloy was re-dissolved into the matrix, effectively decreasing the stress concentration, which was beneficial to the enhancement of elongation. At aging temperatures of $300^{\circ} \mathrm{C}$, Widmanstatten structure, lath-shaped precipitate, and intergranular precipitate were observed, while at $175-200{ }^{\circ} \mathrm{C}$, cellular structure and oval-shaped particle were also identified. The morphology, area fraction, size of the precipitates, and PFZs (precipitate free zones) width worked together to affect the age-hardening behavior of the alloy. The strength and hardness of the peak-aged samples decreased with the increase in aging temperature, which is primarily attributed to the reduction in cellular structure area fraction and the corresponding increase in the interlamellar spacing, and the coarsening of the rhombus precipitate.
\end{abstract}

Keywords AZ80 mg alloy $\cdot$ Annular channel angular extrusion $\cdot$ Heat treatment $\cdot$ Precipitate $\cdot$ Mechanical properties

\section{Introduction}

In recent years, magnesium $(\mathrm{Mg})$ alloys have been widely welcomed in the aerospace field due to their low density, high specific strength, and good electromagnetic shielding $[1,2]$. Die-casting is the most prevalent method of fabricating Mg alloys' products for its established technique and simple operations [3]. However, due to poor room temperature properties, the cast products cannot meet the

Available online at http://link.springer.com/journal/40195.

Xi Zhao

zhaoxi_1111@163.com

1 School of Mechanical and Electrical Engineering, North University of China, Taiyuan 030051, China

2 Ningbo Branch of Chinese Academy of Ordnance Science, Ningbo 315103, China

3 Engineering Technology Research Center for Integrated Precision Forming of Shanxi Province, Taiyuan 030051, China

4 China Aerodynamics Research and Development Center, Mianyang 621000, China requirements of high-end equipment. Therefore, many researchers are devoted to the enhancement of mechanical properties via alloying, large plastic deformation, heat treatment, etc., which is conducive to expanding the application of $\mathrm{Mg}$ products [4-6].

Excellent forging capability, satisfied strength, and low cost make AZ80 alloy one of the most popular commercial wrought $\mathrm{Mg}$ alloys [7]. As the most important additive element in AZ80 alloy, the aluminum can refine the grains and promote the formation of $\beta-\mathrm{Mg}_{17} \mathrm{Al}_{12}$ strengthening phase. A great number of studies have pointed out that the comprehensive performance of AZ80 alloy can be enhanced by adjusting the $\beta-\mathrm{Mg}_{17} \mathrm{Al}_{12}$ precipitate morphologies through heat treatments. Lai et al. [8] obtained different morphologies of $\beta-\mathrm{Mg}_{17} \mathrm{Al}_{12}$ by changing the aging temperature, as well as studied the relationship between precipitate morphology evolution and aging response. Zhao et al. [9] studied the dissolution and precipitation of $\beta-\mathrm{Mg}_{17} \mathrm{Al}_{12}$ phase under solution treatment and aging treatment. Effects of solution and aging treatments on the grain size of as-cast AZ80 alloy, $\beta-\mathrm{Mg}_{17} \mathrm{Al}_{12}$ phase, mechanical properties, and flow asymmetry were investigated by Palai et al. [10]. However, limited number of studies has been devoted to studying the effects 
of the detailed characterization such as the size, distribution, and area fraction of $\beta-\mathrm{Mg}_{17} \mathrm{Al}_{12}$ intermetallic phase on the mechanical properties of AZ80 alloy. The relationship between microstructure and mechanical properties has not been established.

In the previous study, the annular channel angular extrusion technology and different heat treatments were conducted on the as-cast AZ80 Mg alloy [11, 12]. The results indicated that the brittle eutectic phase in the ascast structure adversely affect the deformation and subsequent heat treatments of the alloy. Therefore, in this study, the homogenization treatment is performed on the as-cast alloy to dissolve the brittle eutectic phase. The effects of extrusion and solution treatment on the microstructure and mechanical properties are studied. In particular, the effects of aging treatment on the microstructure evolution, and the $\beta$ - $\mathrm{Mg}_{17} \mathrm{Al}_{12}$ precipitate morphologies, have been investigated. Mechanical properties corresponding to microstructure have been delivered to develop a clearer understanding of various fracture mechanisms at different aging conditions.

\section{Experimental}

The experimental material is commercial as-cast AZ80 Mg alloy (Mg-8.0Al-0.5Zn-0.11Mn, wt\%). The large-sized ingot was subjected to homogenization treatment $\left(415^{\circ} \mathrm{C}+16 \mathrm{~h}\right)$ before processing, after which a cylindrical billet with the height of $360 \mathrm{~mm}$ and the diameter of $90 \mathrm{~mm}$ was cut from the middle of the ingot. Before the extrusion, the billet was preheated at $350{ }^{\circ} \mathrm{C}$ for $3 \mathrm{~h}$ to ensure the consistency of temperature throughout the billet. The extrusion was then carried out at $350{ }^{\circ} \mathrm{C}$ with a punch speed of $0.5 \mathrm{~mm} / \mathrm{s}$. In the annular channel angular extrusion, as shown in Fig. 1a, the cylindrical billet is firstly placed into the mandrel. The billet is then extruded along the gap between the mandrel and the die to form cabin. Detailed operation method has been introduced in our previous studies [11-13]. As shown in Fig. 1b, the samples used in the study were all cut from the wall in the cabin. The samples were then subjected to a solution treatment at $415{ }^{\circ} \mathrm{C}$ for $2 \mathrm{~h}$, which were termed as (a)

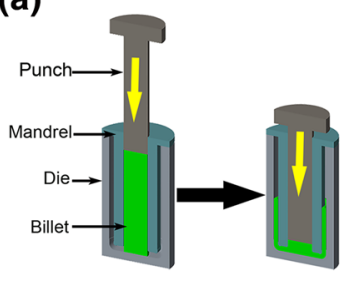

(b)

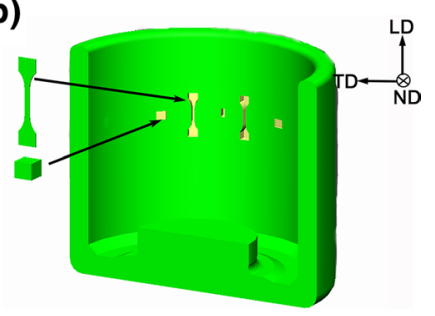

Fig. 1 a Schematic view of the annular channel angular extrusion, $\mathbf{b}$ sampling locations used in this research
T4 samples. Subsequently, the T4 samples were divided into four groups for aging treatment at different temperatures of $175^{\circ} \mathrm{C}, 200{ }^{\circ} \mathrm{C}, 250{ }^{\circ} \mathrm{C}$, and $300{ }^{\circ} \mathrm{C}$. The microstructure of various samples was observed from the LD (longitudinal direction)-ED (transverse direction) plane.

Microstructure and composition of the samples were analyzed by optical microscopy (OM, CARL ZEISS), scanning electron microscopy (SEM, SU5000), and energy dispersive spectrometer (EDS). Samples for OM, SEM were mechanically polished and chemically etched in a solution of $0.4 \mathrm{~g} \mathrm{H}_{2} \mathrm{C}_{2} \mathrm{O}_{4}+1 \mathrm{~mL} \mathrm{CH}_{3} \mathrm{COO}_{\mathrm{H}}+60 \mathrm{~mL}$ distilled water for 5-10 s. Phase analysis was conducted on D/Max2500 X-ray diffraction $(\mathrm{XRD})$ with a $\mathrm{Cu} K_{\alpha}$ radiation $(\lambda=0.154 \mathrm{~nm})$, which was operated at $36 \mathrm{kV}$ in a 2 theta of $20-80^{\circ}$. The average grain size of the samples was measured from OM images by linear intercept method. The area fractions of the $\mathrm{DP}, \mathrm{CP}$, and $\alpha-\mathrm{Mg}$ matrix were determined by averaging the values acquired from five SEM images (magnification: $500 \times$ ) by using an Image-Pro Plus 5.0. For the measurement of precipitate size, the dimension of 100 precipitates was measured from SEM micrographs and the average size is reported. The microhardness was measured using Vickers indenter with a load of $200 \mathrm{~g}$ and a dwell time of $15 \mathrm{~s}$. For the reliability of the tests, 10 indentations were measured under each sample condition. The room temperature tensile tests were carried out on an Instron 5967 electronic tensile machine (Instron Inc., Canton) with an initial strain rate of $1 \times 10^{-3} \mathrm{~s}^{-1}$. Tension samples, whose gauges were $15 \mathrm{~mm}$ in length and $4 \mathrm{~mm}$ in width, were extracted from the wall, and at least 3 samples were tested in each group of experiments. The loading axis of the sample corresponds to the LD.

\section{Results and Discussion}

\subsection{Microstructure of As-Cast and Homogenized Alloys}

Figure $2 \mathrm{a}$ shows the typical structure of as-cast AZ80 Mg alloy, including $\alpha-\mathrm{Mg}$ matrix, divorced eutectic phases of $\beta-\mathrm{Mg}_{17} \mathrm{Al}_{12}$, and $\mathrm{Al}-\mathrm{Mn}$ phases. In molten alloys, $\mathrm{Al}$ atoms enriched at the grain boundaries and formed the dendritic eutectic phase, which is detrimental for the plastic deformation $[14,15]$. After homogenization treatment, the eutectic phase was totally dissolved into the $\alpha$-Mg matrix, with discernible grain boundaries and the average grain size of $420 \mu \mathrm{m}$ (Fig. 2b). Additionally, it is observed that the Al-Mn phase still exists in the matrix due to its high thermal stability. Figure 3 shows the XRD diffraction pattern of the as-cast and homogenized AZ80 Mg alloy. Obviously, the as-cast alloy is mainly composed of $\alpha-\mathrm{Mg}$ and $\beta-\mathrm{Mg}_{17} \mathrm{Al}_{12}$ phase, and there is no obvious diffraction peak due to the small amount of the $\mathrm{Al}-\mathrm{Mn}$ phase. The $\beta-\mathrm{Mg}_{17} \mathrm{Al}_{12}$ diffraction 

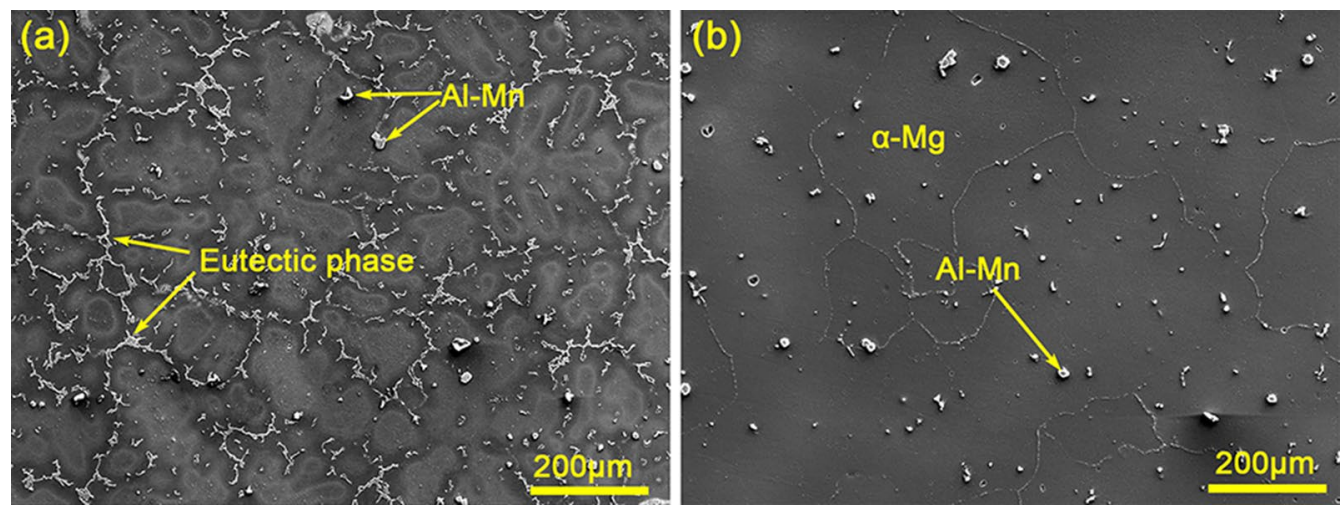

Fig. 2 SEM micrographs of a as-cast, $\mathbf{b}$ homogenized AZ80 Mg alloy

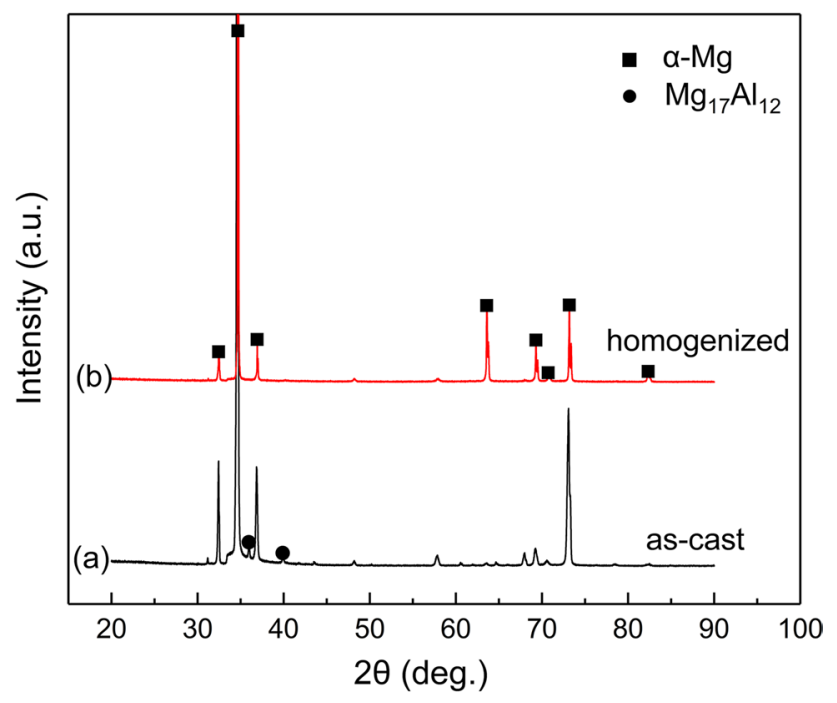

were $\beta-\mathrm{Mg}_{17} \mathrm{Al}_{12}$ (Fig. 5a). The particle in the extruded structure was precipitated during the deformation process, which is the dynamic precipitation. The strain generated in the severe plastic deformation process will lead to the induction of lattice defects, resulting in the segregation of solute atoms and the formation of precipitates [16, 17]. In addition, the precipitation positions of the particle are also in connection with critical strain. Guo et al. [16] reported that during the rolling deformation, the deformation strain increased be equal and greater than $40 \%$, large number of $\beta$ phases start to precipitate in the grain refinement region. This is because the large deformation strain is conducive to the increase in interfacial and strain energy in grain refinement region, and promotes the nucleation of the $\beta$ phase. Therefore, in the initial stage of deformation, fineDRXed grains are formed near the grain boundaries of the original coarse grains, and they accumulate a large number of dislocations and vacancies, which is conducive to dynamic precipitation [18]. Meanwhile, the particles precipitated at the fine grain boundaries have a pinning effect, which makes it difficult for the grains to grow, thus forming fine-grained region [19].

Heterogeneous distribution of dynamic precipitate leads to the imbalance of solute atoms in the alloy. The directaging treatment might cause the strengthening phases to precipitate in an uneven way, which is not conducive to the improvement of the properties. Thus, solid solution treatment was performed on the extruded alloy to eliminate the uneven distribution of solute atoms [20]. As shown in Fig. $4 \mathrm{c}, \mathrm{d}$, a more uniform structure with average grain size of $26.6 \mu \mathrm{m}$ appears in T4 samples. And solution treatment enables the dynamic precipitate to completely dissolve into $\mathrm{Mg}$ matrix, and the insoluble $\mathrm{Al}-\mathrm{Mn}$ phase is retained (Fig. 5b). The above optical and SEM results indicate that the supersaturated $\alpha-\mathrm{Mg}$ solid solution was obtained after solution treatment at $415^{\circ} \mathrm{C}$ for $2 \mathrm{~h}$, thus preparing a good and homogeneous structure for the subsequent aging treatment. 

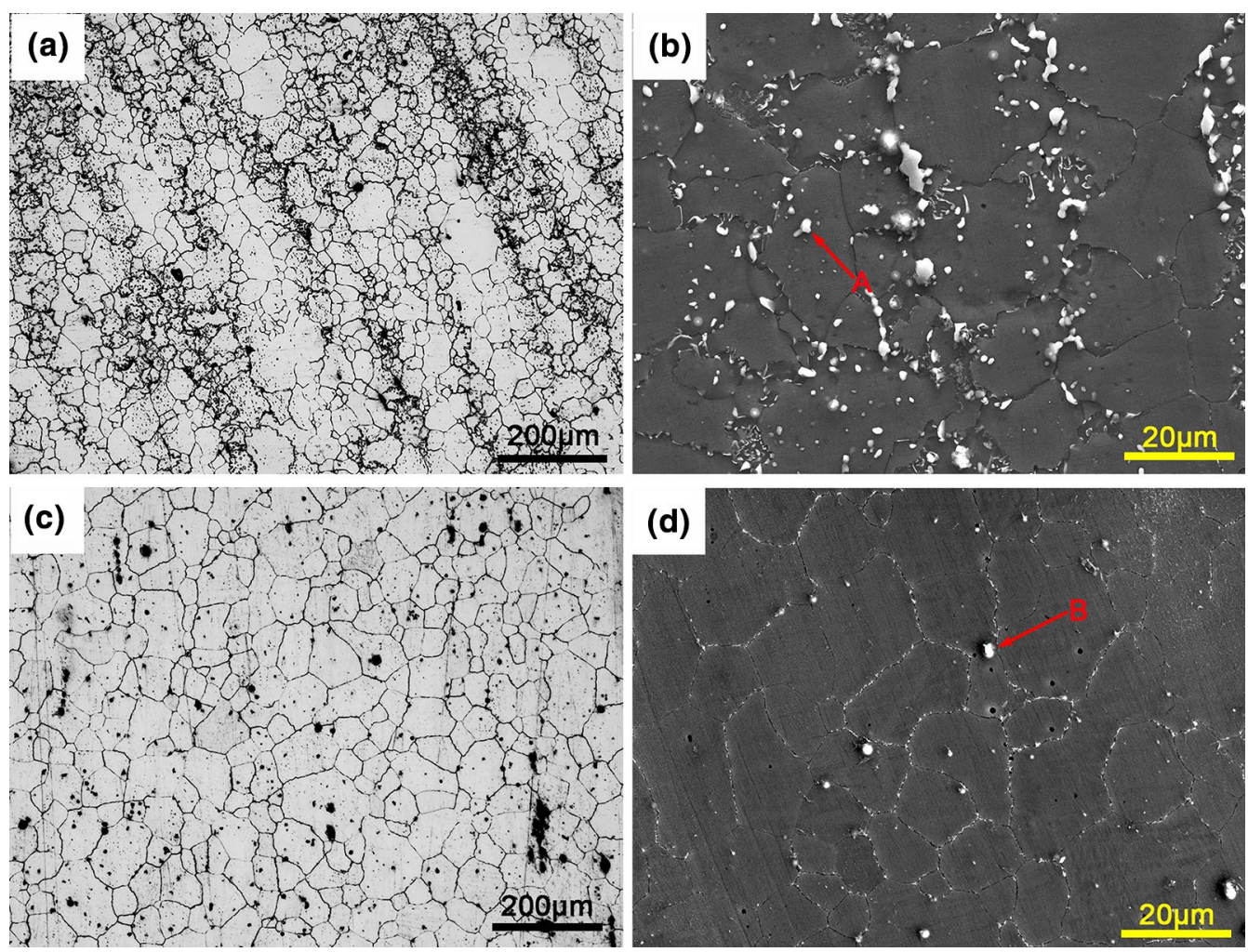

Fig. 4 Microstructures of AZ80 Mg alloy: a, b extruded, $\mathbf{c}, \mathbf{d}$ solution-treated

(a)

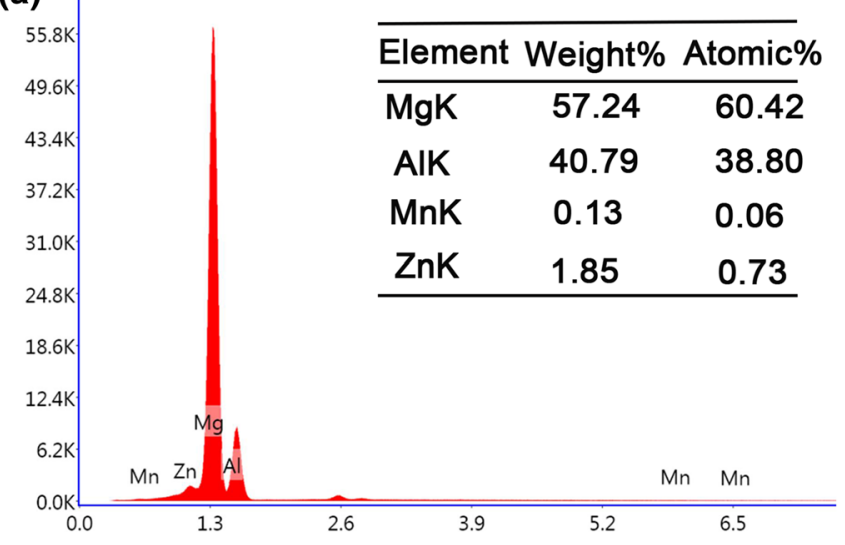

(b)

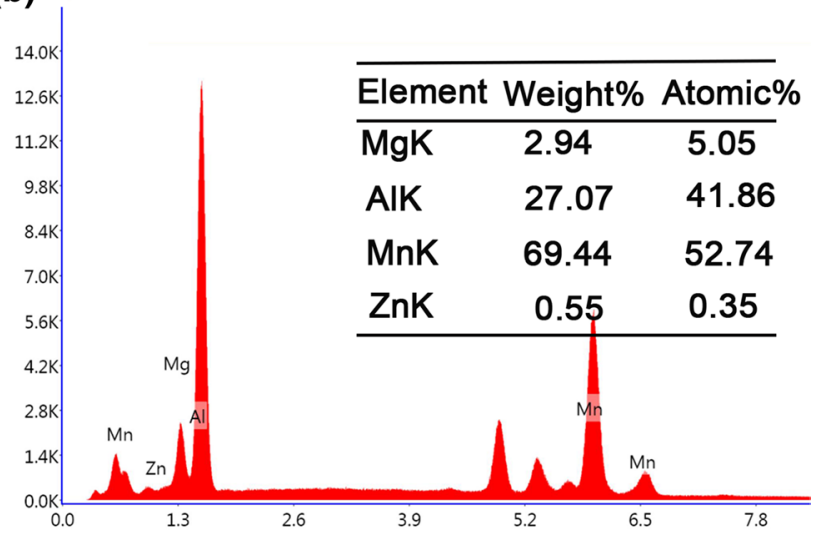

Fig. 5 EDS results of a extruded, $\mathbf{b}$ solution-treated samples

\subsection{Aging Response}

Figure 6 shows the age-hardening response of the solidsolution AZ80 alloy at different temperatures. The variety of hardness of all samples under different aging temperatures shows similar trend, which increases rapidly to the peak value with increasing aging time and then decreases slightly. And the increase in the aging temperature shortens the time required to reach the peak hardness, and reduces the peak hardness. For samples aged at $175{ }^{\circ} \mathrm{C}$, $200{ }^{\circ} \mathrm{C}, 250{ }^{\circ} \mathrm{C}$, and $300{ }^{\circ} \mathrm{C}$, the peak-aging time was $30 \mathrm{~h}$ ( $88 \mathrm{HV}), 24 \mathrm{~h}(85 \mathrm{HV}), 18 \mathrm{~h}(77 \mathrm{HV})$, and $12 \mathrm{~h}(71 \mathrm{HV})$, respectively. The above trend is only applicable to aging temperature above $175^{\circ} \mathrm{C}$. Lai et al. [8] found that when the aging temperature is below $175^{\circ} \mathrm{C}\left(125^{\circ} \mathrm{C}, 150{ }^{\circ} \mathrm{C}\right)$, the hardness increase is not obvious, and did not reach its peak hardness during the time period examined ( $256 \mathrm{~h}$ ). It shows that the second phase is difficult to nucleate and 


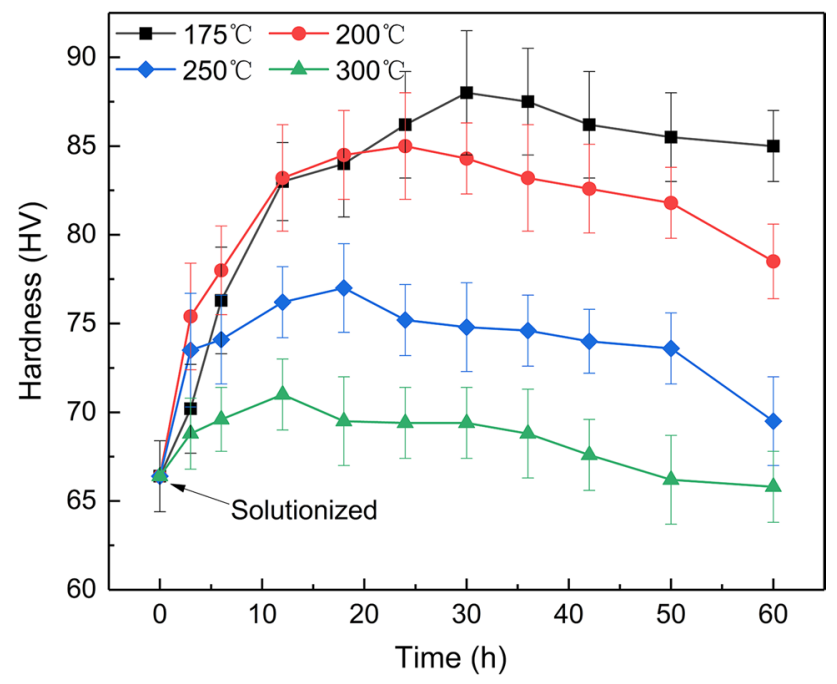

Fig. 6 Age-hardening response of AZ80 Mg alloy at different temperatures

precipitate at very low aging temperature, and the effect of hardening ability is limited.

\subsection{Precipitation Behaviors of $\beta-\mathrm{Mg}_{17} \mathrm{Al}_{12}$ Phase}

With a body-centered cubic (BCC) structure, $\beta-\mathrm{Mg}_{17} \mathrm{Al}_{12}$ is the main strengthening phase of the AZ80 Mg alloy [10, $21]$. The $\beta-\mathrm{Mg}_{17} \mathrm{Al}_{12}$ phase precipitates directly from the $\mathrm{Mg}$ matrix without any intermediate phases or GP zones. Based on the different precipitation methods of $\beta-\mathrm{Mg}_{17} \mathrm{Al}_{12}$, it can be divided into two types, namely, continuous precipitates (CPs) and discontinuous precipitates (DPs) [9]. Possible morphologies of continuous precipitates include lathshaped, rhombic, and a mixture of the two. Morphologies of the discontinuous precipitates include the cellular structure, oval-shaped particles, and intergranular precipitates [22]. In order to study the difference in precipitation order and morphologies of the $\beta-\mathrm{Mg}_{17} \mathrm{Al}_{12}$ at different aging temperatures,
SEM microstructure observation was performed on the initial aging (aging at a certain temperature for $1 \mathrm{~h}$ ) and peakaged samples.

After aging at $175{ }^{\circ} \mathrm{C}$ for $1 \mathrm{~h}$, the lamellar precipitates began to precipitate vertically from the grain boundaries and grow into the grains, forming a cellular structure (Fig. 7a). In the enlarged detail view of the upper right corner of Fig. 7a, it is observed that the oval-shaped particles in the interval of lamellar precipitates. As shown in Fig. 7b, most of the grains in the samples aged for $30 \mathrm{~h}$ are laden with lamellar precipitates, and the lamellar growth directions in different grains are different. In addition, a large number of irregular rhombus precipitates (the morphology is shown in the embedded blue block diagram) and a mixture of lath-shaped and rhombus precipitates (the morphology is shown in the embedded cyan block diagram) are found in the remaining grains. A small amount of granular intergranular precipitates are distributed at the grain boundaries.

The SEM image of sample aged for $1 \mathrm{~h}$ at $200{ }^{\circ} \mathrm{C}$ is similar to that in Fig. 7a. Figure 8 shows the SEM structure of the sample aged at $200{ }^{\circ} \mathrm{C}$ for $24 \mathrm{~h}$. The proportion of cellular structure precipitated along the grain boundary decreased, while the area fraction of CP precipitated in the grains increased (Fig. 8a). The SEM images of higher magnifications show that there are three morphologies of the precipitates within the grains (Fig. 8b). The lath-shaped precipitates are parallel to each other and maintain a highly oriented direction (Fig. 8c). The irregular rhombus precipitates are arranged at an $60^{\circ}$ to each other, which is the Widmannstatten structure (Fig. 8d). Meanwhile, the lath-shaped precipitates are mixed with the rhombus precipitates to form complex and disordered precipitates (Fig. 8d). It is worth mentioning that precipitates with different morphologies occupy different regions, which were clearly separated by grain boundaries, as shown by the red line mark in Fig. 8b. In the region near to the grain boundary, the distinct precipitate free zones (PFZs) were formed [23]. Only the discrete intergranular precipitates are identified in PFZs.
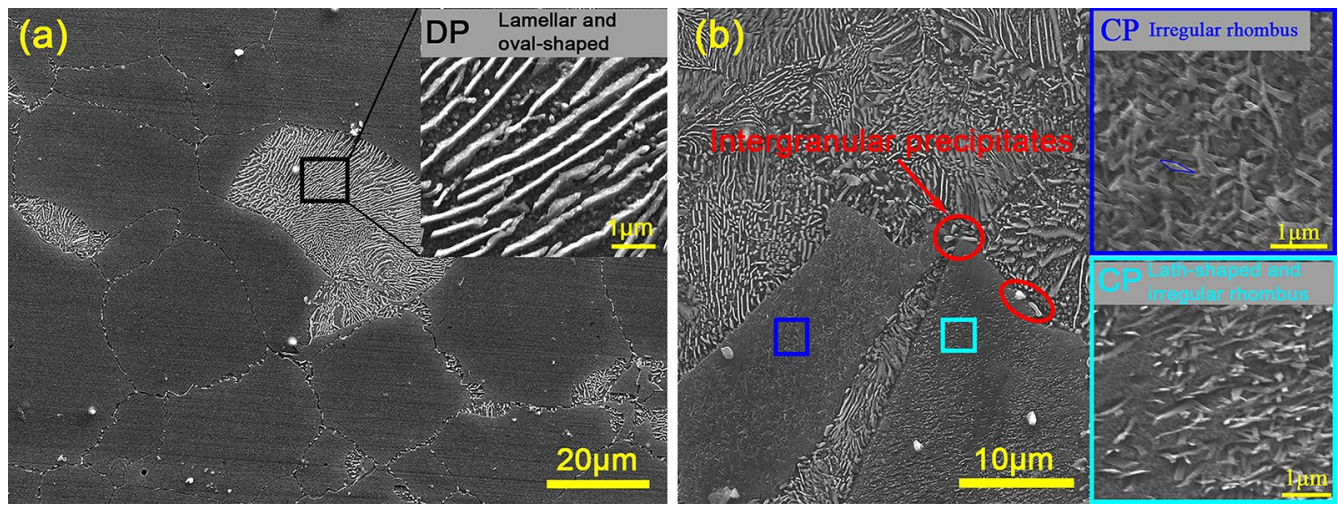

Fig. 7 SEM micrographs of AZ80 alloy aged at $175^{\circ} \mathrm{C}$ for a $1 \mathrm{~h}, \mathbf{b} 30 \mathrm{~h}$ 

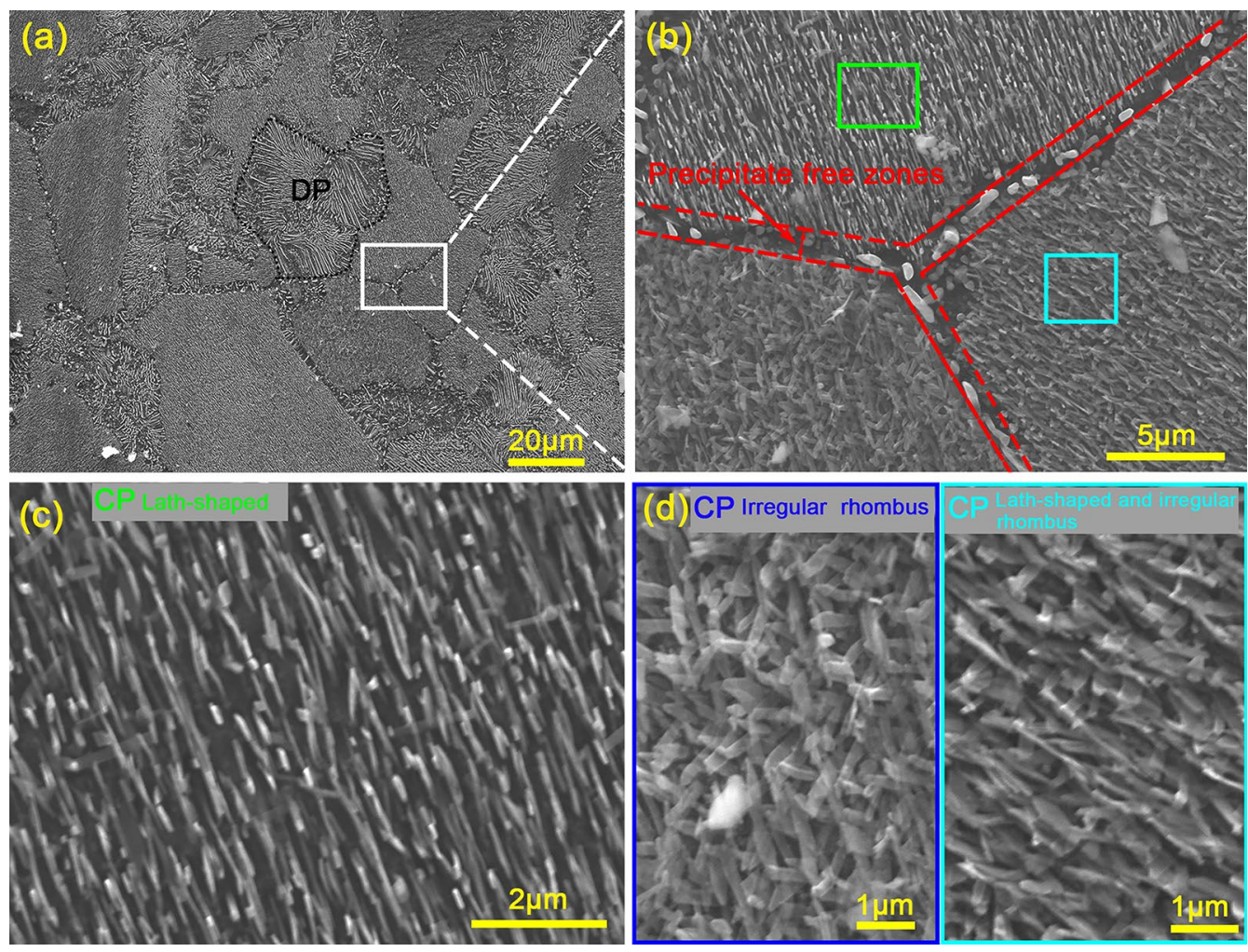

Fig. 8 SEM micrographs of AZ80 alloy aged at $200{ }^{\circ} \mathrm{C}$ for $24 \mathrm{~h}$

Figure $9 \mathrm{a}, \mathrm{b}$ shows the microstructure aged at $250{ }^{\circ} \mathrm{C}$ for $1 \mathrm{~h}$. In addition to the cellular structure precipitated from the grain boundaries, high-density precipitates are observed within the grains (Fig. 9a). According to Fig. 9b, the morphology of the precipitate is a mixture of the rhombus precipitate and lathshaped precipitate, which are different from that in Fig. 8d. It was reported that the lath-shaped precipitate and the rhombus precipitate are not uniformly mixed, and the proportion of them is uncertain, for which the morphology of the mixture is not unique [24]. After aging for $18 \mathrm{~h}$, the oriented lath-shaped precipitates (green frame in Fig. 9d) and the irregular rhombus precipitates (blue frame in Fig. 9d) are observed in the sample. In addition, the PFZs and intergranular precipitates were found at the interface between the cellular structure and continuous precipitates (Fig. 9c). And the size of the intergranular precipitates increases up and forms lumps.

As the aging temperature increased to $300{ }^{\circ} \mathrm{C}$, the microstructure of the alloy changed obviously. After aging for $1 \mathrm{~h}$, a large number of lath-shaped precipitates, rhombus precipitates, and intergranular precipitates were identified in the sample, while no cellular structure was found (Fig. 10a). As the aging time was extended to $12 \mathrm{~h}$, there was still no cellular structure or oval-shaped particles in the sample. Long-term aging makes the rhombus precipitate continue to coarsen, the thickness to increase, and the shape to be irregular (Fig. 10b). In addition, aging at high temperature of $300{ }^{\circ} \mathrm{C}$ increases the solid solubility of the $\mathrm{Al}$ element in the $\alpha$-Mg matrix and reduces the amount of precipitate. In the sample aged for $12 \mathrm{~h}$, there are still a large amount of grains that do not form precipitates, as shown in the red frame in Fig. 10b.

Through comprehensive comparison among Figs. 7, 8, 9, 10 , it is found that the variation of aging temperature changes the precipitation sequence and morphologies of the precipitate. When the aging temperature is lower than $200{ }^{\circ} \mathrm{C}$, the cellular structure and oval-shaped particle are preferentially precipitated at the grain boundary in a short time. When the temperature is higher than $250{ }^{\circ} \mathrm{C}$, the lath-shaped precipitate and Widmanstatten structure will precipitate at the initial aging. Table 1 shows the relationship between the different aging temperatures and precipitation morphology of the phases. In the temperature range of 175 to $300{ }^{\circ} \mathrm{C}$, the Widmanstatten structure, lath-shaped precipitate, and intergranular precipitate will precipitate from the supersaturated solid solution. In the range of 175 to $250^{\circ} \mathrm{C}$, the oval-shaped particles and cellular structure will precipitate along the grain boundary. With the temperature increases to $300{ }^{\circ} \mathrm{C}$, the cellular structure and the oval-shaped particles are inhibited and will not precipitate. These evidences show that DP tends to occur at low temperatures while the high-temperature aging promotes the $\mathrm{CP}$, which is consistent with previous studies $[22,25]$. As is known to all, the precipitation behavior of DP and CP are competitive. Braszczynska-Malik [26] reported 

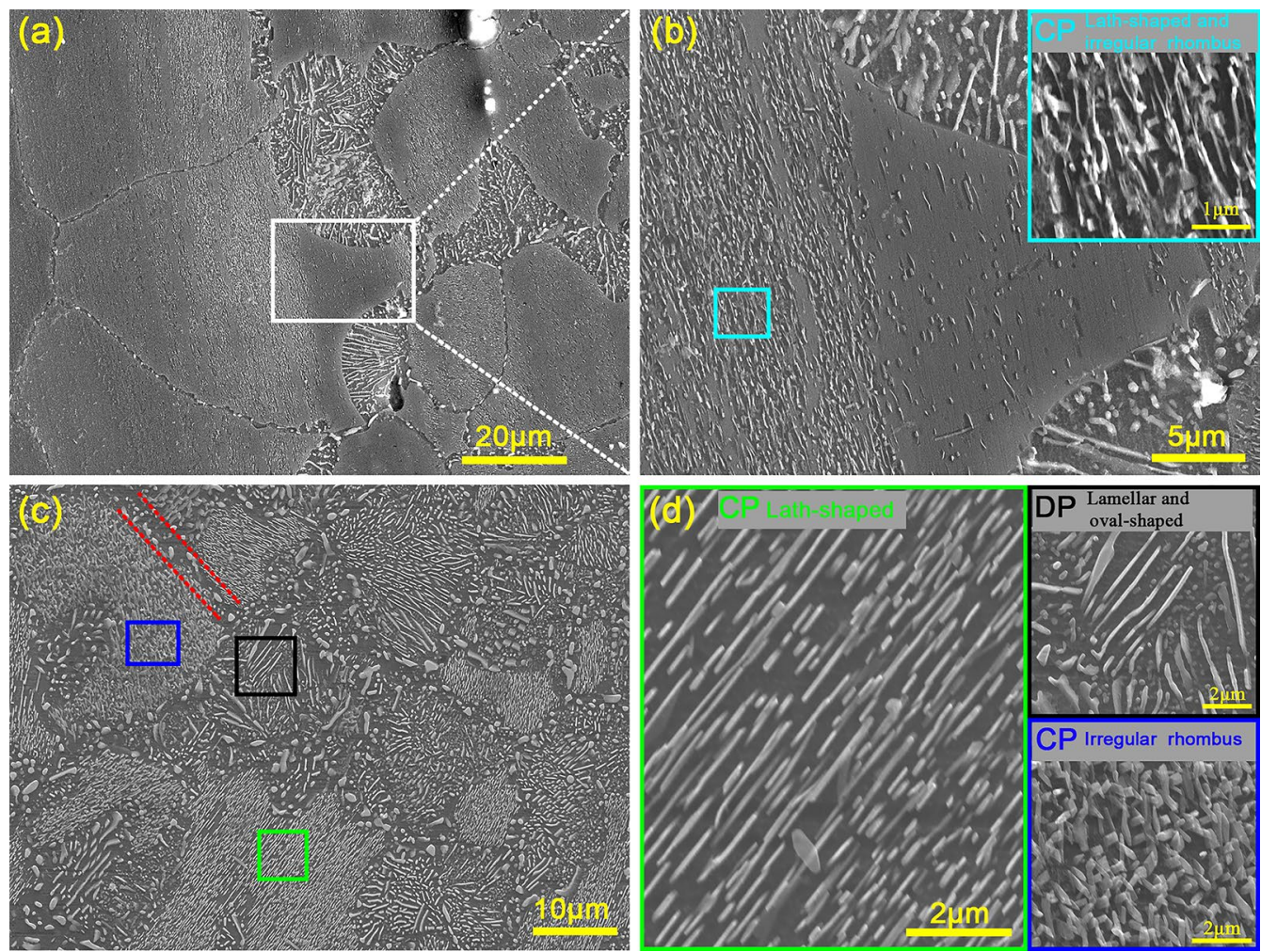

Fig. 9 SEM micrographs of AZ80 alloy aged at $250^{\circ} \mathrm{C}$ for $\mathbf{a}, \mathbf{b} 1 \mathrm{~h}, \mathbf{c}, \mathbf{d} 18 \mathrm{~h}$
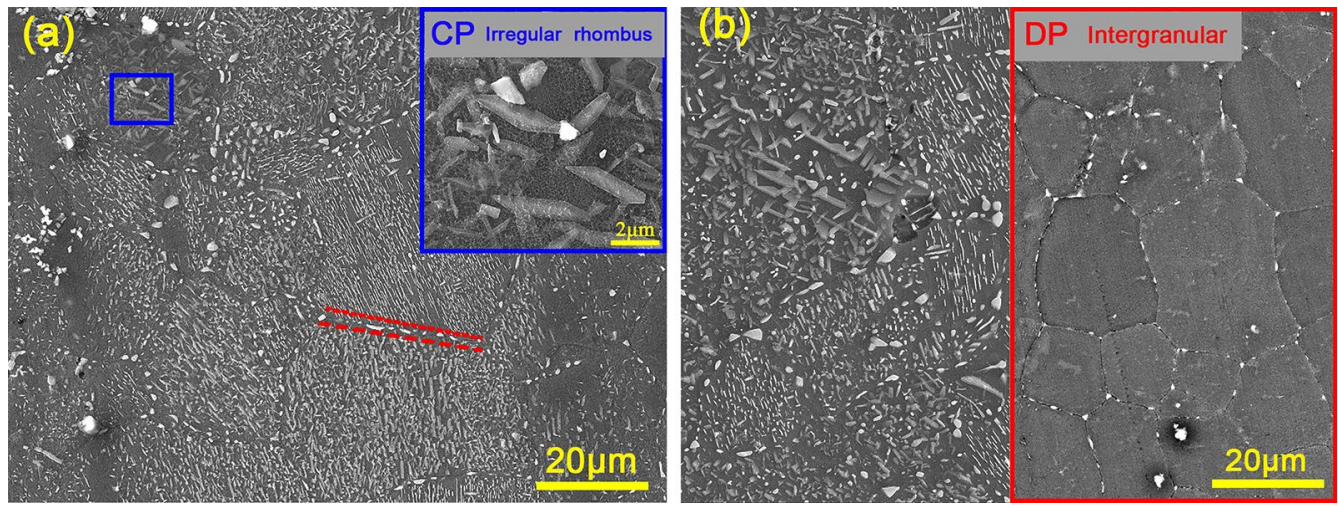

Fig. 10 SEM micrographs of AZ80 alloy aged at $300{ }^{\circ} \mathrm{C}$ for $\mathbf{a} 1 \mathrm{~h}, \mathbf{b} 12 \mathrm{~h}$

Table 1 Aging temperature ranges of various kinds of precipitates

\begin{tabular}{ll}
\hline Precipitate morphologies & $\begin{array}{l}\text { Aging tem- } \\
\text { perature }\left({ }^{\circ} \mathrm{C}\right)\end{array}$ \\
\hline Widmanstatten structure & $175-300$ \\
Lath-shaped precipitate & $175-300$ \\
Intergranular precipitate & $175-300$ \\
Cellular structure & $175-250$ \\
Oval-shaped precipitate & $175-250$ \\
\hline
\end{tabular}

that the precipitation mode is concerned with the diffusion process of solute atoms. At low temperatures, grain boundary diffusion dominates the precipitation behavior, enhancing the driving force of the DP. Volume diffusion is activated at high temperatures, and the chemical driving force of the DP is reduced, which is favorable for the precipitation of the CP.

Table 2 summarizes the precipitate size and PFZ width of the peak-aged samples. Due to the large variation in the size of precipitates observed, size ranges, instead of average values, are given. The change of the interlamellar spacing in the cellular structure is more obvious than that in length, and the interlamellar spacing is counted in the table. As the aging 
Table 2 Precipitate size $(\mu \mathrm{m})$ and PFZ width $(\mu \mathrm{m})$ of the peak-aged samples

\begin{tabular}{|c|c|c|c|c|c|c|c|c|c|}
\hline \multirow{3}{*}{ Aging condition } & \multicolumn{4}{|c|}{ Continuous precipitates } & \multicolumn{4}{|c|}{ Discontinuous precipitates } & \multirow{3}{*}{$\begin{array}{l}\text { PFZ } \\
\text { Width }\end{array}$} \\
\hline & \multicolumn{2}{|l|}{ Rhombus } & \multicolumn{2}{|c|}{ Lath-shaped } & \multicolumn{2}{|l|}{ Lamellar } & \multirow{2}{*}{$\begin{array}{l}\text { Oval-shaped } \\
\text { Diameter }\end{array}$} & \multirow{2}{*}{$\begin{array}{l}\text { Intergranular } \\
\text { Diameter }\end{array}$} & \\
\hline & Length & Width & Length & Width & Width & Spacing & & & \\
\hline $175^{\circ} \mathrm{C}-30 \mathrm{~h}$ & $0.30-0.70$ & $0.07-0.20$ & $0.20-1.50$ & $0.08-0.15$ & $0.10-1.00$ & $0.24-0.45$ & $0.10-0.30$ & $0.30-0.80$ & $0.04-0.06$ \\
\hline $200{ }^{\circ} \mathrm{C}-24 \mathrm{~h}$ & $0.70-1.00$ & $0.15-0.35$ & $0.20-1.50$ & $0.08-0.15$ & $0.10-1.00$ & $0.40-1.00$ & $0.20-0.40$ & $0.50-1.00$ & $0.50-1.00$ \\
\hline $250{ }^{\circ} \mathrm{C}-18 \mathrm{~h}$ & $0.80-1.20$ & $0.20-0.40$ & $0.20-3.00$ & $0.08-0.15$ & $0.30-1.50$ & $0.60-1.50$ & $0.20-0.40$ & $0.70-2.00$ & $1.20-2.50$ \\
\hline $300{ }^{\circ} \mathrm{C}-12 \mathrm{~h}$ & $2.50-8.00$ & $1.00-2.50$ & $0.30-3.50$ & $0.08-0.20$ & - & - & - & $1.00-3.00$ & $1.50-3.00$ \\
\hline
\end{tabular}

temperature increases, interlamellar spacing of cellular structure, the rhombus precipitate size, and intergranular precipitate diameter increases gradually. Especially, in the sample aged at $300{ }^{\circ} \mathrm{C}$ for $12 \mathrm{~h}$, the cellular structure disappeared, and the rhombus precipitate size grew up significantly (Fig. 10b). In contrast, the effect of aging temperature on the size of the lath-shaped precipitate and oval-shaped particle is not obvious. This coarsening of precipitates is termed "Ostwald ripening" phenomenon [27]. On account of the larger curvature and higher energy, the small particles tend to transition to larger particles with lower energy and more stability. It is worth noting that the increase in the size of the intergranular precipitate is accompanied by the increase in the width of the PFZs. The PFZ width of the sample aged at $175^{\circ} \mathrm{C}$ for $30 \mathrm{~h}$ was relatively narrow, only $0.04-0.06 \mu \mathrm{m}$. As the aging temperature increases, the width of the PFZ increases significantly, reaching $1.5-3.0 \mu \mathrm{m}$ in the sample aged at $300{ }^{\circ} \mathrm{C}$ for $12 \mathrm{~h}$. Studies have shown that solute depletion is the main mechanism of PFZ formation [28]. At high aging temperature, volume diffusion becomes the dominant diffusion mechanism, which promotes the precipitation of $\mathrm{CP}$ in the grains, leading to the depletion of solutes near the grain boundaries and the increase in the width of the PFZ.

To illustrate the effects of the amount of precipitation on the age-hardening response of the alloy, the area fraction of precipitate at different temperatures was calculated in Fig. 11. The area fraction of the precipitate increased steadily as a function of the aging time before reaching the peak and then remained stable. The sample aged at $175^{\circ} \mathrm{C}, 200^{\circ} \mathrm{C}, 250^{\circ} \mathrm{C}$, and $300{ }^{\circ} \mathrm{C}$ reached their peak area fraction of the precipitate after aging time of $50 \mathrm{~h}(82.5 \%), 36 \mathrm{~h}(93.2 \%), 30 \mathrm{~h}(81.0 \%)$, $18 \mathrm{~h}(55.0 \%)$, respectively. This indicates the aging temperature determines the amount of precipitate. The increase in the aging temperature can effectively increase the solubility of $\mathrm{Al}$ atoms in the matrix, resulting in a lower strengthening phase fraction in high-temperature aging. In addition, it takes less aging time for the sample to reach the peak hardness than to reach the peak area fraction of the precipitate. Before reaching the peak aging, the increase in the amount of precipitates lead to the increase in the hardness of the alloy, thus showing a strengthening effect on the alloy (Fig. 6). After the peak

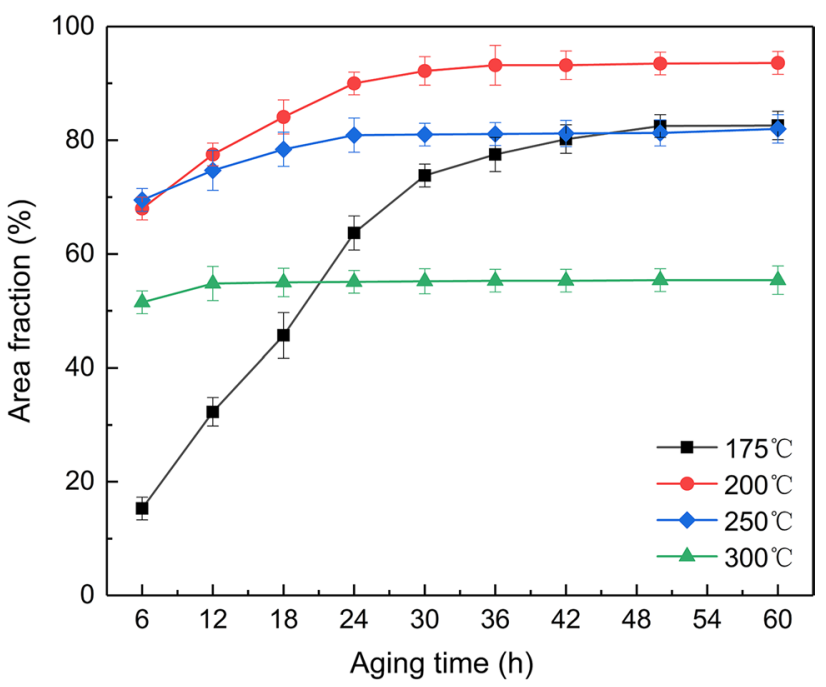

Fig. 11 Variation in area fraction of precipitates with aging time

aging, the fraction of the precipitate is still increasing, while corresponding hardness values decreased slightly. Similar downtrend was also observed in the as-cast AZ92 alloy by Kim et al. [29], which was subjected to $24 \mathrm{~h}$ solution treatment at $420^{\circ} \mathrm{C}$ and subsequently aging at $200{ }^{\circ} \mathrm{C}$ for different lengths of time. They concluded the trend was attributed to the phases coarsened gradually with increasing aging time.

To analyze the effects of precipitate morphology on the hardness improvement, the area fractions and hardness of DP, $\mathrm{CP}$, and $\alpha-\mathrm{Mg}$ matrix in the peak-aged samples were investigated, as shown in Fig. 12. Further, since the area fraction of intergranular precipitate is relatively small, the statistics of the DP mainly refers to the cellular structure. As can be seen in Fig. $12 \mathrm{a}$, as the aging temperature increase from 175 to $300{ }^{\circ} \mathrm{C}$, the area fraction of DP in the peak-aged samples decreased from $48.0 \%$ to $0 \%$. The fraction of CP maintained a high and stable value $(55 \%)$ above $200{ }^{\circ} \mathrm{C}$. DP hardness is significantly higher than $\mathrm{CP}$ and $\alpha$-Mg matrix, as shown in Fig. 12b. This is because DP is mainly composed cellular structure precipitated near the grain boundary with high $\mathrm{Al}$ solute concentration [25]. It is worth noting that the DP and CP hardness of the peak-aged samples gradually decreased with the increase in the 

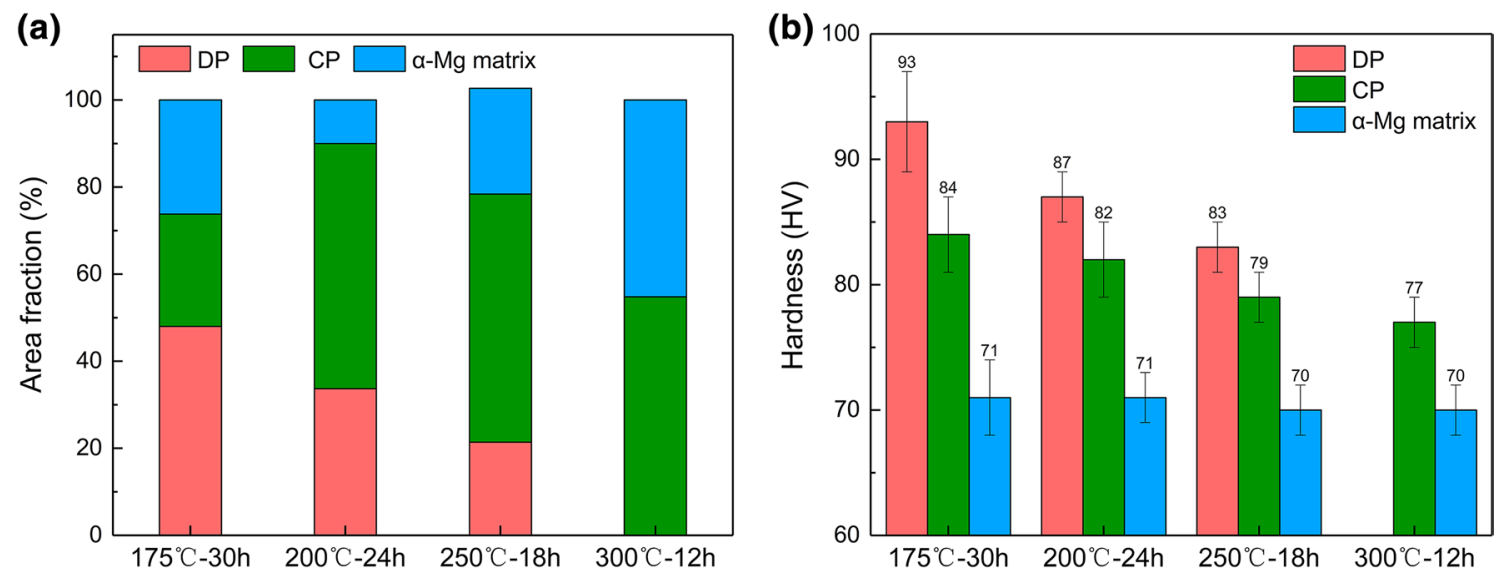

Fig. 12 a Area fraction and $\mathbf{b}$ hardness of DP, CP, and $\alpha$-Mg matrix of peak-aged samples

aging temperature. This result is related to the increase in the interlamellar spacing of the cellular structure and the coarsening of the rhombus phase (Table 2). Therefore, as the aging temperature increases, the area fraction of hard DP decreases and the coarsening of the precipitates lead to a downward tendency in peak-aged hardness.

\subsection{Mechanical Properties}

Figure 13 shows the tensile stress-strain curves of AZ80 samples in different conditions, and Table 3 lists their corresponding tensile properties. Through the annular channel angular extrusion, the AZ80 Mg alloys achieved the ultimate tensile strength (UTS) of $292 \mathrm{MPa}$ with an appropriate tensile elongation (EL) of $15.5 \%$ (Fig. 13a). This is attributed to the combined effect of grain refinement and precipitation strengthening in the extruded sample [30]. The UTS and tensile yield strength (TYS) of the extruded sample after solution treatment decreased due to the grain growth and dissolution of $\beta$ - $\mathrm{Mg}_{17} \mathrm{Al}_{12}$ precipitates (Fig. 4c, d). However, solution treatment makes microstructure uniform and increases elongation (EL) of the alloy (19.1\%). For the T4 sample after peakaging treatment, TYS and UTS increased and EL decreased (Fig. 13b). Especially, the T4 sample aged at $175^{\circ} \mathrm{C}$ for $30 \mathrm{~h}$ exhibits well-mechanical properties, which are better than peak-aged samples at other temperature (UTS and EL of $327 \mathrm{MPa}$ and $11.6 \%$, respectively). It is worth noting that the downward tendency of the TYS and UTS with the increase in aging temperature for peak-aged samples is exactly the same as the variation tendency of the hardness shown in Fig. 6. Table 3 shows that in the peak-aging state, the grain size of the samples at different temperatures is basically the same. Therefore, variations of the precipitate behaviors caused by the increase in aging temperature result in hardening effect
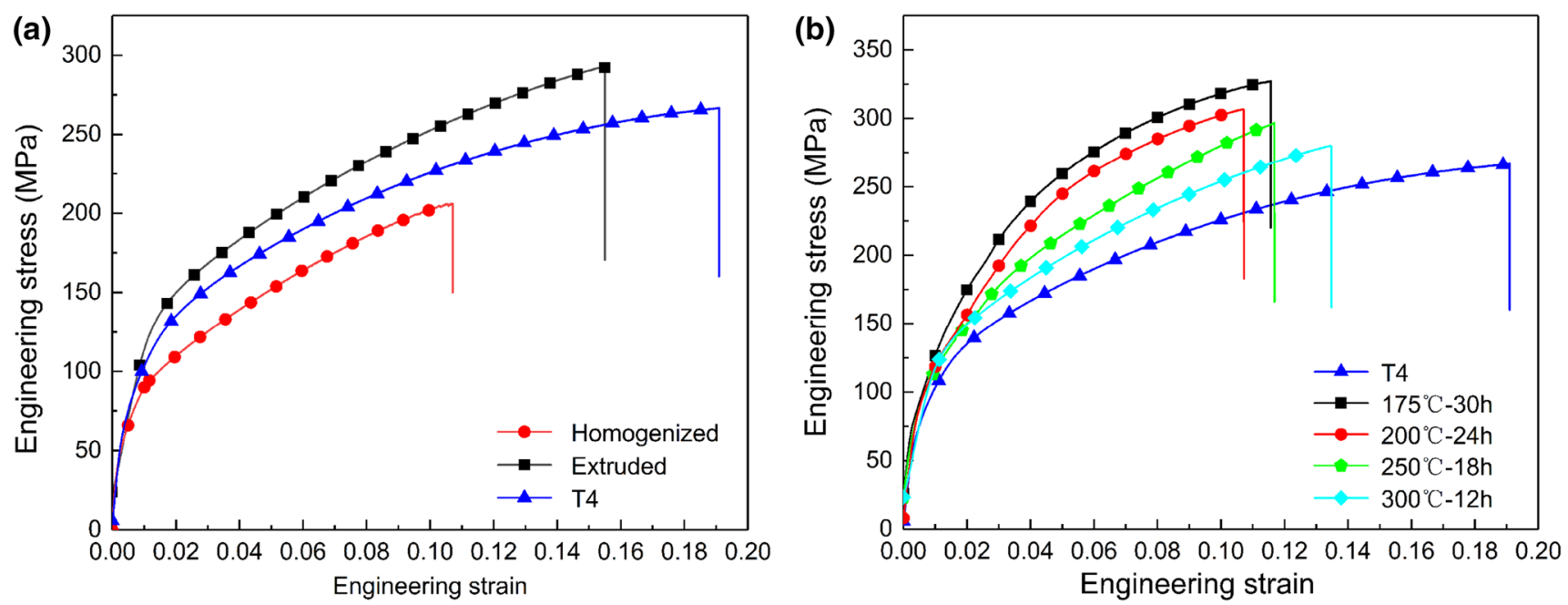

Fig. 13 Tensile curves of a homogenized, extruded and T4 samples, b peak-aged samples at different temperatures 
Table 3 Microstructural characteristics and tensile properties of peak-aged samples

\begin{tabular}{|c|c|c|c|c|c|c|c|}
\hline \multirow[t]{2}{*}{ Ageing schedule } & \multicolumn{4}{|c|}{ Microstructural characteristics $^{\mathrm{a}}$} & \multicolumn{3}{|c|}{ Tensile properties $^{\mathrm{b}}$} \\
\hline & $d(\mu \mathrm{m})$ & $f_{\beta}(\%)$ & $f_{\mathrm{DP}}(\%)$ & $f_{\mathrm{CP}}(\%)$ & UTS (MPa) & TYS (MPa) & $\mathrm{El}(\%)$ \\
\hline Homogenized & $420.0( \pm 5.0)$ & - & - & - & $206( \pm 8)$ & $97( \pm 6)$ & $10.7( \pm 1.1)$ \\
\hline Extruded & $23.7( \pm 2.5)$ & - & - & - & $292( \pm 7)$ & $165( \pm 4)$ & $15.5( \pm 0.8)$ \\
\hline $\mathrm{T} 4$ & $26.6( \pm 1.5)$ & 0 & 0 & 0 & $267( \pm 4)$ & $148( \pm 2)$ & $19.1( \pm 0.5)$ \\
\hline $175^{\circ} \mathrm{C}-30 \mathrm{~h}$ & $27.4( \pm 1.5)$ & $73.8( \pm 1.5)$ & $48.0( \pm 1.5)$ & $25.8( \pm 1.7)$ & $327( \pm 13)$ & $225( \pm 9)$ & $11.6( \pm 1.2)$ \\
\hline $200^{\circ} \mathrm{C}-24 \mathrm{~h}$ & $28.6( \pm 1.8)$ & $90.0( \pm 1.5)$ & $33.7( \pm 1.8)$ & $56.3( \pm 2.0)$ & $306( \pm 10)$ & $203( \pm 7)$ & $10.7( \pm 1.3)$ \\
\hline $250{ }^{\circ} \mathrm{C}-18 \mathrm{~h}$ & $29.1( \pm 2.0)$ & $78.4( \pm 2.0)$ & $21.4( \pm 2.0)$ & $57.0( \pm 2.2)$ & $297( \pm 8)$ & $185( \pm 5)$ & $11.7( \pm 0.9)$ \\
\hline $300{ }^{\circ} \mathrm{C}-12 \mathrm{~h}$ & $29.3( \pm 2.0)$ & $54.8( \pm 2.5)$ & 0 & $54.8( \pm 2.5)$ & $279( \pm 7)$ & $176( \pm 5)$ & $13.5( \pm 0.7)$ \\
\hline
\end{tabular}

differences of the peak-aged samples, which in turn affect the tensile properties. On the one hand, as the aging temperature increases from 175 to $300{ }^{\circ} \mathrm{C}$, the relative area fraction of the DP in the peak-aged sample decreases (Fig. 12a). It is reported that the habit plane of most CPs is parallel to the basal plane of $\alpha$-Mg matrix [24]. Discontinuous precipitation cellular structure can impede dislocation movement, and play a very important role for strengthening the alloys [26, 31]. On the other hand, in the sample aged at high temperatures, interlamellar spacing of the cellular structure increased, the rhombus precipitates coarsened, which results in the decrease in the ability to block the motion of the dislocations.

Figure 14 shows the SEM images near the fracture of the tensile sample in different states. Microcracks formed along the intergranular precipitate are observed on the tensile fracture surface in the extruded sample (Fig. 14a). During the tensile tests, the intergranular precipitate hinders the lattice dislocation and grain boundaries, promoting the stress concentration and crack formation in the grain boundaries $[32,33]$. In the fractured tensile specimens of the T4 samples, deformation twins and microcracks formed along these twins are observed in the matrix (Fig. 14b). The twins with low critical shearing stress (CRSS) values are easily activated during the deformation due to the limited slip systems of $\mathrm{Mg}$ alloys at room temperature [34]. Therefore, the T4 sample formed deformed twins during tensile deformation, and cracks were generated due to stress concentration in the formed twin bands. As shown in Fig. 14c-f, the peak-aged samples exhibit the same fracture behavior during tensile deformation, that is, cracks formed at the interface between the precipitates and the $\alpha-\mathrm{Mg}$ matrix $[35,36]$. In the fractured tensile specimens at $175-250{ }^{\circ} \mathrm{C}$, cracks initiated at the PFZs between the brittle cellular structure and the matrix. The cracks in the fractured sample at $300{ }^{\circ} \mathrm{C}$ initiated near the grain boundary of intergranular precipitate. By means of nanoindentation, Zindal et al. [28] reported that the PFZs are
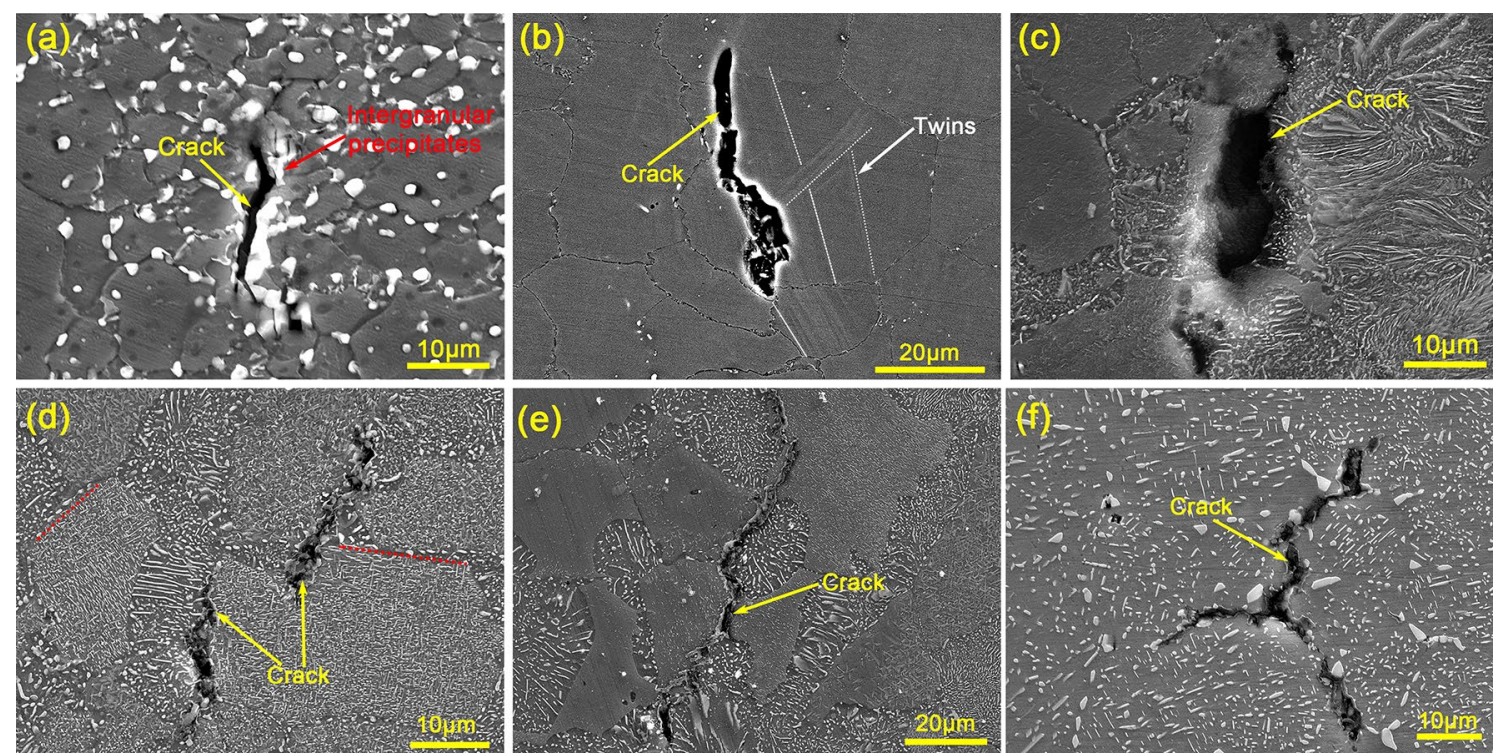

Fig. 14 SEM images near the fractured surfaces of AZ80 alloys after tensile tests: a extruded, b T4, c $175{ }^{\circ} \mathrm{C}-30 \mathrm{~h}, \mathbf{d ~} 200{ }^{\circ} \mathrm{C}-24 \mathrm{~h}, \mathbf{e} 250{ }^{\circ} \mathrm{C}$ $-18 \mathrm{~h}, \mathbf{f} 300^{\circ} \mathrm{C}-12 \mathrm{~h}$ 
a typical soft region. This means that in the peak-aging states, the brittle precipitates and $\alpha-\mathrm{Mg}$ matrix deformation are not coordinated, leading to the cracks initiation and expansion in the PFZs, which induced the fracture of the alloy.

\section{Conclusions}

In this work, the effects of different aging temperatures on the precipitation behavior and microstructure evolution of AZ80 Mg alloy are systematically studied, especially the relationship between the phase morphology, area fraction, size, PFZ width, and mechanical properties. The conclusions drawn are as follows:

1. After the annular channel angular extrusion, the grains are significantly refined $(23.7 \mu \mathrm{m})$, and the intergranular precipitate is the main reason for the fracture of the alloy. After the solution treatment, the alloy structure is a uniform supersaturated solid solution, and the fracture mechanism is transformed into twin-induced fracture.

2. Within the examined temperature range $\left(175-300{ }^{\circ} \mathrm{C}\right)$, low temperature is conducive to the precipitation of cellular structure and oval-shaped particle, while aging at high temperature is beneficial to the precipitation of Widmanstatten structure, lath-shaped precipitate and intergranular precipitate. When the aging temperature is higher than $300^{\circ} \mathrm{C}$, no cellular structure or oval-shaped particle precipitates in the sample.

3. As the aging temperature increases, the hardness and tensile strength of peak-aged samples decreases, which is mainly attributed to the to the shrinking area fraction of cellular structure and the corresponding increase in the interlamellar spacing, and the coarsening of the rhombus precipitate.

4. During the tensile tests at room temperature, cracks tend to nucleate and propagate in the PFZ between the $\alpha-\mathrm{Mg}$ matrix and the precipitate, resulting in final fracture of the peak-aged samples.

Acknowledgements This work was financially supported by the "HIGHGRADE CNC machine tools and basic manufacturing equipment" Major National Science and technology projects (2019ZX04022001-004) and the Military research Projects (JPPT-2019-021).

\section{References}

[1] J.H. Zhang, S.J. Liu, R.Z. Wu, L.G. Hou, M.L. Zhang, J. Magnes. Alloy. 6, 277 (2018)

[2] B.J. Wang, J.Y. Luan, D.K. Xu, J. Jun, C.Q. Li, E.H. Han, Acta Metall. Sin. -Engl. Lett. 32, 1 (2019)

[3] B.J. Wang, D.K. Xu, S.D. Wang, E.H. Han, Front. Mech. Eng. 14, $113(2019)$
[4] S. Sepahi-Boroujeni, A. Sepahi-Boroujeni, J. Manuf. Process. 24, 71 (2016)

[5] Q. Ji, Y.J. Ma, R.Z. Wu, J. Zhang, L.G. Hou, M.L. Zhang, J. Alloys Compd. 800, 72 (2019)

[6] Y. Uematsu, K. Tokaji, M. Matsumoto, Mater. Sci. Eng. A 517, 138 (2009)

[7] A. Gryguc, S.K. Shaha, S.B. Behravesh, H. Jahed, M. Wells, B. Williams, X. Su, Int. J. Fatigue 104, 136 (2017)

[8] W.J. Lai, Y.Y. Li, Y.F. Hsu, S. Trong, W.H. Wang, J. Alloys Compd. 476, 118 (2009)

[9] D.G. Zhao, Z.Q. Wang, M. Zuo, H.R. Geng, Mater. Des. 56, 589 (2014)

[10] P. Palai, N. Prabhu, P.D. Hodgson, B.P. Kashyap, J. Mater. Eng. Perform. 23, 77 (2014)

[11] X. Zhao, S.C. Li, F.F. Yan, Z.M. Zhang, Y.J. Wu, Materials 12, $4223(2019)$

[12] X. Zhao, S.C. Li, Y. Xue, Z.M. Zhang, Materials 12, 1001 (2019)

[13] P.C. Gao, X. Zhao, F.F. Yan, S.C. Li, Z.M. Zhang, Mater. Res. Express. 6, 126578 (2019)

[14] S.W. Xu, S. Kamado, T. Honma, Mater. Sci. Eng. A 528, 2385 (2011)

[15] C.J. Wang, K.K. Deng, K.B. Nie, S.J. Shang, W. Liang, Mater. Sci. Eng. A 656, 102 (2016)

[16] F. Guo, D.F. Zhang, X.S. Yang, L.Y. Jiang, F.S. Pan, Mater. Sci. Eng. A 636, 516 (2015)

[17] E. Dogan, S. Wang, M.W. Vaughan, I. Karaman, Acta Mater. 116, 1 (2016)

[18] F. Zhong, H.J. Wu, Y.L. Jiao, R.Z. Wu, J.H. Zhang, L.G. Hou, M.L. Zhang, J. Mater. Sci. Technol. 39, 124 (2020)

[19] S.W. Xu, N. Matsumoto, S. Kamado, T. Honma, Y. Kojima, Mater. Sci. Eng. A 523, 47 (2009)

[20] B.J. Wang, D.K. Xu, S.D. Wang, L.Y. Sheng, R.C. Zeng, E.H. Han, Int. J. Fatigue 120, 46 (2019)

[21] S.S. Chai, D.F. Zhang, T. Tang, F. Guo, F.S. Pan, Mater. Sci. Eng. A 646, 66 (2015)

[22] S.L. Yu, Y.H. Gao, C.M. Liu, X.Z. Han, J. Alloys Compd. 646, $431(2015)$

[23] A. Zindal, J. Jain, R. Prasad, S.S. Singh, Mater. Lett. 201, 207 (2017)

[24] S. Celotto, Acta Mater. 48, 1775 (2000)

[25] J.U. Lee, S.H. Kim, Y.J. Kim, S.H. Park, Mater. Sci. Eng. A 714, 49 (2018)

[26] K.N. Braszczynska-Malik, J. Alloys Compd. 477, 870 (2009)

[27] P.E. Di Nunzio, Philos. Mag. (Abingdon) 99, 2858 (2019)

[28] A. Zindal, J. Jain, R. Prasad, S.S. Singh, R. Sarvesha, P. Cizek, M.R. Barnett, Mater. Charact. 136, 175 (2018)

[29] S.H. Kim, J.U. Lee, Y.J. Kim, J.H. Bae, B.S. You, S.H. Park, J. Mater. Sci. Technol. 34, 265 (2018)

[30] X.J. Zhou, J. Zhang, X.M. Chen, X. Zhang, M.J. Li, J. Alloys Compd. 787, 551 (2019)

[31] D. Bradai, M. Kadi-hanifi, P. Zieba, W.M. Kuschke, W. Gust, J. Mater. Sci. 34, 5331 (1999)

[32] X. Zhao, P.C. Gao, Z.M. Zhang, Q. Wang, F.F. Yan, Fatigue characteristics of the extruded AZ80 automotive wheel. Int. J. Fatigue 132, 105393 (2020)

[33] B. Chen, D.L. Lin, L. Jin, X.Q. Zeng, C. Lu, Mater. Sci. Eng. A 483, 113 (2008)

[34] S.H. Kim, S.W. Lee, B.G. Moon, H.S. Kim, Y.M. Kim, S.H. Park, J. Mater. Res. Technol. 8, 5254 (2019)

[35] Y.M. Liu, L. Wang, G. Chen, B.B. Li, X.H. Wang, Mater. Sci. Eng. A 743, 314 (2019)

[36] G. Zeng, S.L. Yu, Y.H. Gao, C.M. Liu, X.Z. Han, Mater. Sci. Eng. A 645, 273 (2015) 